\title{
The structure of problem behaviours among Irish adolescents
}

\author{
JOEL W. GRUBE \& MARK MORGAN
}

Published in: British Journal of Addiction, 1990, 85 pp.667-675

Copyright: Wiley-Blackwell

\begin{abstract}
Problem behaviour theory proposes that adolescent substance use and other problem behaviours comprise a single dimension reflecting a general underlying tendency towards deviance. This general deviance hypothesis was tested with survey data obtained/row 2731 adolescents/row Dublin, Ireland. A series of hierarchical maximum likelihood factor analyses indicated that three specific factors were necessary to account for the co-variation among problem behaviour measures. These factors corresponded to substance use (drinking, smoking, marijuana use, and other drug use), relatively minor problem behaviours (swearing, lying), and relatively serious problem behaviours (stealing, vandalism). Contrary to the general deviance hypothesis, a second order factor representing general deviance accounted for only $14 \%$ of the variance in substance use, on the average, as opposed to $74 \%$ of the variance in minor and serious problem behaviours. These findings thus indicate that substance use among these Irish adolescents is relatively independent of a general tendency toward deviance. They also suggest that the general deviance hypothesis, as it usually is applied, may be culturally specific and relevant only for adolescents from the United States and similar cultural contexts.
\end{abstract}

Problem behaviour theory proposes that adolescent smoking, drinking, drug use, and other problem behaviours form a single dimension that reflects a more general underlying tendency to non-conformity or deviance (e.g. Jessor \& Jessor, 1977; Donovan \& Jessor, 1978). In support of this general deviance hypothesis, proponents of problem behaviour theory have pointed out that research consistently shows that a wide range of adolescent problem behaviours are positively correlated with one another and appear to be influenced in a similar fashion by the same variables (e.g. Jessor \& Jessor,. 1977; Johnston et al, 1978; Donovan \& Jessor, 1985). More direct evidence for the general deviance hypothesis has been provided by factor analytic studies of problem behaviours. For example, Donovan \& Jessor (1985) showed that there is a single common factor underlying a number of problem behaviours among adolescents including drunken- ness, marijuana use, shoplifiting, vandalism, and frequency of sexual intercourse. Moreover, conventionality (church attendance) school performance) loaded on this factor, but in a negative direction. Other more recent studies (Osgood et al, 1988; Newcomb \& Bender, 1988) also have found that a single dimension of general deviance accounts for the majority of the covariance among specific problem behaviours and that this factor is predictive of involvement in these behaviours at a latter point in time.

Although the available evidence for the general deviance hypothesis appears to be persuasive, it is largely based on research with samples of adolescents and young adults from the United States. Thus, it is possible that this hypothesisis is relevant only to a particular cultural context. Adolescent problem behaviours in other countries may be multidimensional and more complex. The present paper addresses this issue by investigating the structure underlying problem behaviours in a sample of Irish post-primary students. On the basis of previous research (Grube $\&$

Morgan, 1986), it was hypothesized that problem behaviours in this sample would be multidimensional. Specifically, it was expected that at least two district dimensions underlying problem behaviours would be found, one corresponding to substance use behaviours and the second to other problem behaviours. The possibility that the structure of problem behaviours was even more complex was considered also. 


\section{Method}

Procedure

Overview. Data were obtained from Irish post- primary students using self-administered questionnaires given on two occasions approximately one month apart. The survey instruments were similar in format for the two sessions. However, the instrument used in the first session emphasized smoking beliefs, attitudes, and behaviours while that used in the second session emphasized drinking, drug use, other problem behaviours, and related variables.

The surveys were administered to the students in group settings in their regular classrooms by trained interviewers. Approximately 45 minutes were required to complete the survey. Before each session, the interviewer explained that the study was concerned with smoking, drinking, and other drug use. The students were assured as to the confidentiality of their responses and were told that their participation in the survey was strictly voluntary. The need for truthful answers was emphasized and the students were specifically instructed not to put their names on the survey materials. The surveys were matched over the testing sessions through the use of self-generated codes (Grube, Morgan \& Kearney, 1989). Details concerning the procedures, survey instruments, and variables may be found in Grube \& Morgan (1986).

Sample. The target population consisted of post- primary students in the greater Dublin, Ireland area. A sample of 24 schools, stratified for gender composition, size, and type of school (secondary, community/comprehensive, or vocational) was obtained. Within each school all students from a randomly selected grade level were included in the study.

Data were obtained from 2927 students at the first session and 2782 students at the second session. They were nearly evenly divided between males (51\%) and females (49\%) and ranged in reported age from just over 9 to 21 years old. However, the vast majority (99.7\%) fell between 12 and 18 and the median age was about 15 years. Because of missing data on single items, the analyses that follow are based on 2731 students.

\section{Measures}

The primary measures of substance use were current smoking, drinking, and drug use. For smoking, the respondents were asked to indicate on an 8-point scale how many cigarettes they had smoked each day during the previous month, (none-more than 20). For drinking, the respondents were asked on a 7-point scale the number of times they had taken a whole drink of cider, beer, wine, and spirits during the previous month (none-more than 10). An overall measure of current drinking behaviour was obtained by summing the items for the individual beverages $(a=0.73)$. Drug use was ascertained by having the students indicate on a similar scale how many times they had used each of 10 classes of drugs during the past month (non- more than 10). Marijuana use was considered separately and a measure of other drug use was obtained by averaging the number of times each student had used each of the other drugs $(\mathrm{a}=0.88)$. The items' response categories were rescaled using interval midpoint values and an average score over the two testing sessions was obtained for each of the substance use behaviours. Involvement in other problem behaviours was measured by asking the respondents to indicate on 5-point scales how often (never-very often) they engaged in each of five behaviours: swearing, lying to parents, lying to teachers, stealing and vandalizing property. The means and standard deviations for each of the variables are shown in Table 1 . To help reduce skewness and to more nearly equalize the variances, a square root transformation was applied before the primary data analyses 


\section{Results}

Table 1. Means and standard deviations for problem behaviour and drug use measures.

\begin{tabular}{|c|c|c|c|c|c|c|c|c|c|c|}
\hline Group & $\mathrm{n}$ & Smoking & Drinking & Marijuana & $\begin{array}{r}\text { Other drug } \\
\text { use } \\
\end{array}$ & $\begin{array}{l}\text { Lying to } \\
\text { teachers }\end{array}$ & $\begin{array}{r}\text { Lying to } \\
\text { parents }\end{array}$ & Swearing & Stealing & Vandalism \\
\hline \multirow[t]{2}{*}{ Males $<14$} & 420 & 1.33 & 2.95 & 0.27 & 0.23 & 2.96 & 2.78 & 4.09 & 2.33 & 2.04 \\
\hline & & (3.68) & (5.78) & (1.46) & (1.15) & (1.19) & (1.10) & (1.03) & (1.26) & (1.21) \\
\hline \multirow[t]{2}{*}{ Females <14 } & 626 & 0.80 & 1.10 & 0.11 & 0.08 & 2.44 & 2.54 & 3.81 & 1.66 & 1.34 \\
\hline & & $(2.42)$ & $(3.21$ & $(0.84)$ & $(0.65)$ & (1.14) & (1.05) & (1.12) & $(0.96)$ & $(0.74)$ \\
\hline \multirow[t]{2}{*}{ Males 15-16 } & 584 & 2.38 & 4.66 & 0.44 & 0.16 & 3.22 & 3.00 & 4.31 & 2.27 & 2.02 \\
\hline & & $(4.40)$ & $(6.06)$ & (1.65) & $(0.84)$ & (1.17) & (1.14) & $(0.90)$ & (1.18) & (1.16) \\
\hline \multirow{2}{*}{ Females 15-16 } & 488 & 1.62 & 2.35 & 0.19 & 0.09 & 2.88 & 2.73 & 4.11 & 1.65 & 1.39 \\
\hline & & (3.68) & $(4.02)$ & $(0.93)$ & $(0.58)$ & (1.08) & (1.08) & $(1.02)$ & $(0.94)$ & $(0.75)$ \\
\hline \multirow[t]{2}{*}{ Males >17 } & 353 & 2.60 & 6.42 & 0.52 & 0.11 & 3.23 & 2.99 & 4.20 & 2.09 & 1.73 \\
\hline & & (4.89) & (7.42) & (1.65) & $(0.64)$ & (1.15) & (1.09) & $(0.88)$ & (1.11) & (1.00) \\
\hline \multirow{2}{*}{ Females $>17$} & 236 & 2.32 & 3.39 & 0.24 & 0.04 & 2.66 & 2.53 & 3.94 & 1.57 & 1.16 \\
\hline & & $(4.58)$ & $(4.64)$ & (1.04) & $(0.19)$ & (1.07) & (1.00) & $(0.95)$ & $(0.82)$ & (0.53) \\
\hline \multirow[t]{2}{*}{ Total sample } & 2731 & 1.75 & 3.44 & 0.31 & 0.13 & 2.89 & 2.77 & 4.08 & 1.95 & 1.64 \\
\hline & & (3.95) & (5.88) & (1.39) & $(0.79)$ & (1.18) & (1.11) & $(1.02)$ & (1.12) & (1.01) \\
\hline
\end{tabular}

Note: Standard deviations are given in parentheses. The Total sample is slightly larger than the sum of the subgroups because of missing data on age and gender. Scale values for smoking range from 0-25; for drinking, marijuana, and other drug use from 0-12; and for other problem behaviours from $1-5$.

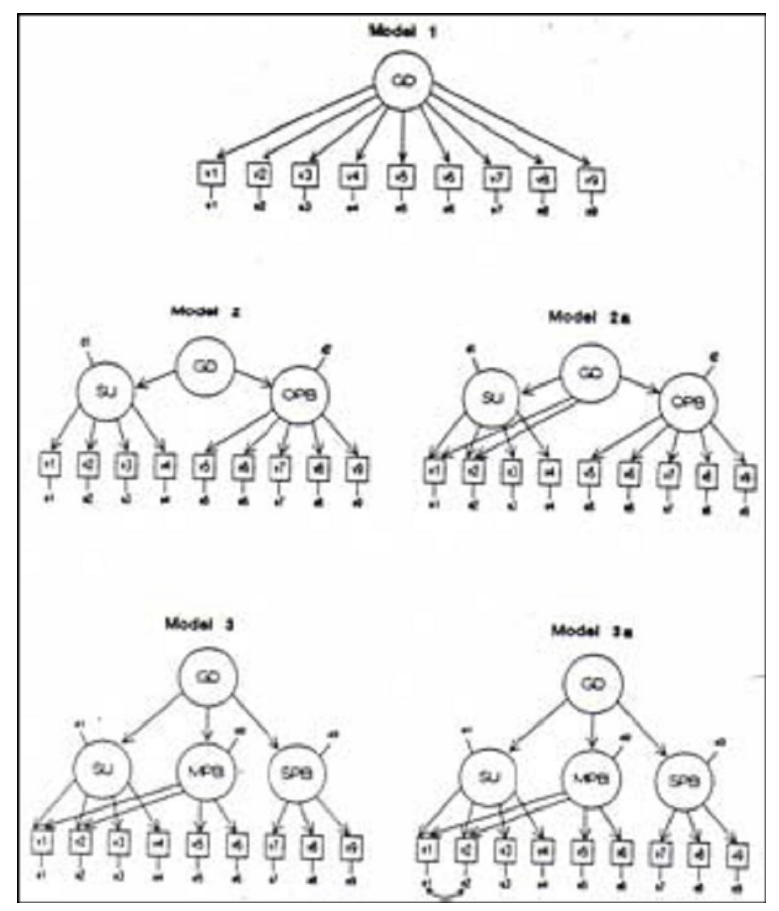

Figure 1. Alternative models of the structure a/problem behaviours. Note: v1 = cigarette smoking; $\mathrm{v} 2=$ drinking v $3=$ marijuana use; $\mathrm{v} 4=$ other drug use; v5 = stealing; v6 = vandalism; v7 = lying to teachers; v8 = lying to parents; v9 = swearing; GD = general deviance; SU = substance use; OPB9 other problem behaviours; SPB = more serious problem behaviours; MPB = minor problem behaviours; el-e99 errors in observed variables; $\mathrm{dl}-\mathrm{d} 3=$ disturbances in structural equations.

The main analyses consisted of a series of maximum likelihood factor analyses using EQS (Bender, 1985). The five models shown in Fig. 1 were compared. Model 1 comprised a one factor solution, corresponding to the structure previously found for American samples (e.g. Donovan \& Jessor, 1985). ${ }^{1}$ Model 2 consisted of a two-factor solution with dimensions corresponding to (a) drug use and (b) other problem behaviours. The interpretation of a multiple factor solution is complicated in this case because it is unclear to what extent the dimensions are substantive in nature or reflect methods factors resulting from the use of different measurement scales.

Thus, a higher order factor representing general deviance was specified also. ${ }^{2}$ The structural coefficients relating this second order factor to the lower order factors can be interpreted as indicating the extent to which the covariation in specific dimensions of problem behaviour can be attributed to a common underlying predisposition.

\footnotetext{
1 This model was identified by fixing one of the factor loadings at 1

2 This model was identified by fixing one loading at 1 on each primary factor, by placing equality constraints on the disturbances for the two primary factors, and by fixing the variance of the second order factor at 1 (e.g. Bender, 1985)
} 
Because the latent variables or factors are independent of method, these structural coefficients should be unaffected by the fact that different measurement scales were used for the observed variables. A specification search at this point using Language

Table 2. Comparison of factor models of problem behaviours

\begin{tabular}{|c|c|c|c|c|c|c|c|}
\hline Model & $\mathbf{X}^{2}$ & df & $\mathbf{p}$ & Fit Index & Difference $\mathbf{X}^{2}$ & df & $\mathbf{p}$ \\
\hline & \multicolumn{7}{|c|}{ Males 14 years old and under } \\
\hline Model 1 & 643.47 & 27 & 0.001 & 0.57 & & & \\
\hline Model 2 & 218.47 & 26 & 0.001 & 0.85 & 425.00 & 1 & 0.001 \\
\hline Model 2a & 153.87 & 24 & 0.001 & 0.90 & 64.60 & 2 & 0.001 \\
\hline Model 3 & 99.56 & 23 & 0.001 & 0.93 & 54.31 & 1 & 0.001 \\
\hline \multirow[t]{2}{*}{ Model 3a } & 61.52 & 22 & 0.001 & 0.96 & 38.04 & 1 & 0.001 \\
\hline & \multicolumn{7}{|c|}{ Females 14 years old and under } \\
\hline Model 1 & 798.10 & 27 & 0.001 & 0.63 & & & \\
\hline Model 2 & 351.58 & 26 & 0.001 & 0.84 & 446.52 & 1 & 0.001 \\
\hline Model 2a & 160.80 & 24 & 0.001 & 0.93 & 190.78 & 2 & 0.001 \\
\hline Model 3 & 105.70 & 23 & 0.001 & 0.95 & 55.10 & 1 & 0.001 \\
\hline \multirow[t]{2}{*}{ Model 3a } & 80.40 & 22 & 0.001 & 0.96 & 25.30 & 1 & 0.001 \\
\hline & \multicolumn{7}{|c|}{ Males $15-16$ years old } \\
\hline Model 1 & 495.08 & 27 & 0.001 & 0.76 & & & \\
\hline Model 2 & 272.81 & 26 & 0.001 & 0.87 & 222.27 & 1 & 0.001 \\
\hline Model 2a & 234.67 & 24 & 0.001 & 0.89 & 38.14 & 2 & 0.001 \\
\hline Model 3 & 106.42 & 23 & 0.001 & 0.95 & 128.25 & 1 & 0.001 \\
\hline \multirow[t]{2}{*}{ Model 3a } & 68.70 & 22 & 0.001 & 0.97 & 37.72 & 1 & 0.001 \\
\hline & \multicolumn{7}{|c|}{ Females $15-16$ years old } \\
\hline Model 1 & 591.31 & 27 & 0.001 & 0.62 & & & \\
\hline Model 2 & 247.20 & 26 & 0.001 & 0.84 & 344.11 & 1 & 0.001 \\
\hline Model 2a & 199.99 & 24 & 0.001 & 0.87 & 47.21 & 2 & 0.001 \\
\hline Model 3 & 131.32 & 23 & 0.001 & 0.92 & 68.67 & 1 & 0.001 \\
\hline \multirow[t]{2}{*}{ Model 3a } & 54.13 & 22 & 0.001 & 0.97 & 77.19 & 1 & 0.001 \\
\hline & \multicolumn{7}{|c|}{ Males 17 years old or older } \\
\hline Model 1 & 317.11 & 27 & 0.001 & 0.68 & & & \\
\hline Model 2 & 148.35 & 26 & 0.001 & 0.85 & 168.76 & 1 & 0.001 \\
\hline Model 2a & 134.49 & 24 & 0.001 & 0.87 & 13.86 & 2 & 0.001 \\
\hline Model 3 & 46.37 & 23 & 0.001 & 0.95 & 88.12 & 1 & 0.001 \\
\hline \multirow[t]{2}{*}{ Model 3a } & 34.95 & 22 & 0.001 & 0.97 & 11.42 & 1 & 0.01 \\
\hline & \multicolumn{7}{|c|}{ Females 17 years old or older } \\
\hline Model 1 & 235.48 & 27 & 0.001 & 0.61 & & & \\
\hline Model 2 & 102.59 & 26 & 0.001 & 0.83 & 132.89 & 1 & 0.001 \\
\hline Model 2a & 79.53 & 24 & 0.001 & 0.87 & 23.06 & 2 & 0.001 \\
\hline Model 3 & 59.46 & 23 & 0.001 & 0.90 & 20.07 & 1 & 0.001 \\
\hline \multirow[t]{2}{*}{ Model 3a } & 34.11 & 22 & 0.001 & 0.94 & 25.35 & 1 & 0.001 \\
\hline & \multicolumn{7}{|c|}{ Total sample } \\
\hline Model 1 & 2648.55 & 27 & 0:001 & 0.70 & & & \\
\hline Model 2 & 1250.94 & 26 & 0.001 & 0.86 & 1397.61 & 1 & 0.001 \\
\hline Model 2a & 951.10 & 24 & 0.001 & 0.89 & 299.84 & 2 & 0.001 \\
\hline Model 3 & 393.20 & 23 & 0.001 & 0.96 & 557.90 & 1 & 0.001 \\
\hline Model 3a & 186.71 & 22 & 0.001 & 0.98 & 206.49 & 1 & 0.001 \\
\hline
\end{tabular}

Multiplier tests suggested that two of the drug items (smoking and drinking) might load significantly on the problem behaviour factor. Model 2a thus included these cross loadings. Model 3 comprised a three-factor solution (drug use, serious problem behaviours, minor problem behaviours). ${ }^{3}$ This model also allowed smoking and drinking to load on both the drug use factor and the minor problem behaviours factor. A final specification search indicated that the fit of the model might be unproved by allowing for a correlated error between smoking and drinking. Model 3a included this correlation.

\footnotetext{
${ }^{3}$ To identify the models and to avoid convergence problems, equality constraints were placed on the disturbances associated with the two problem behaviour factors in Models 3 and 3a. The Lagrange Multiplier tests indicated that relaxation of this constraint would only marginally affect the fit of the models. As with Model 2, one loading on each primary factor and the variance of the second order factor were fixed at 1
} 
Table 3. Standardised factor loadings for final model of problem behaviours

Problem behaviour

Smoking

Drinking

Marijuana use

Other drug use

Lying to teachers

Lying to parents

Swearing

Stealing

Vandalism

Smoking

Drinking

Marijuana use

Other drug use

Lying to teachers

Lying to parents

Swearing

Stealing

Vandalism

Smoking

Drinking

Marijuana use

Other drug use

Lying to teachers

Lying to parents

Swearing

Stealing

Vandalism

Smoking

Drinking

Marijuana use

Other drug use

Lying to teachers

Lying to parents

Swearing

Stealing

Vandalism

Smoking

Drinking

Marijuana use

Other drug use

Lying to teachers

Lying to parents

Swearing

Stealing

Vandalism

Smoking

Drinking

Marijuana use

Other drug use

Lying to teachers

Lying to parents

Swearing

Stealing

Vandalism

Smoking

Drinking

Marijuana use

Other drug use

Lying to teachers

Lying to parents

Swearing

Stealing

Vandalism
Factor

Drug Use Minor Problem Behaviours

Serious Problem Behaviours

Males 14 years old and under

$\begin{array}{rr}0.46^{1} & 0.24 * * * \\ 0.39 * * * & 0.28 * * * \\ 0.83 * * * & \\ 0.92 * * * & \\ & 0.79 * * * \\ & 0.79 * * * \\ & 0.62 * * *\end{array}$

$0.78^{1}$

$0.79 * * *$

Females 14 year old and under

$0.22^{1} \quad 0.40^{* * *}$

$0.30 * * * \quad 0.40 * * *$

$0.97 * * *$

$0.84 * * *$

$0.76^{* * * *}$

$0.74 * * *$

$0.54 * * *$

$0.75^{1}$

$0.76^{* * * *}$

Males 15-16 year old

$\begin{array}{rr}0.33^{1} & 0.28 * * * \\ 0.38 * * * & 0.32 * * * \\ 0.78^{* * *} & \\ 0.71^{* * *} & \\ & 0.83^{1} \\ & 0.84 * * * \\ & 0.63^{* * * *}\end{array}$

$0.84 * * *$

$0.63 * * *$

$0.83^{*}$

$0.85 * * *$

Females 15-16 years old

$0.44^{1}$

$0.35 * * *$

$0.79 * * *$

$0.90 * * *$

$0.30 * * *$

$0.76^{1}$

$0.81 * * *$

$0.59 * * *$

$0.68^{1}$

$0.81 * * *$

Males 17 years old and older

$0.37^{1}$

$0.54 * * *$

$0.79 * * *$

$0.65 * * *$

$0.26 * * *$

0.13 *

$0.72^{1}$

$0.88 * * *$

$0.60 * * *$

$0.79^{1}$

Females 17 years old and older

$0.43^{1} \quad 0.22^{* *}$

$0.37 * * * \quad 0.32 * * *$

$0.84 * * *$

$0.72 * * *$

$0.79^{1}$

$0.73 * * *$

$0.60 * * *$

$0.75^{1}$

$0.38^{1}$

Total sample

$0.62 * *$

$0.26 * * *$

$0.32 * * *$

$0.83 * * *$

$0.76^{* * * *}$

$0.81^{1}$

$0.80 * * *$

$0.61 * * *$

${ }^{*} \mathrm{p}<0.05 * * \mathrm{p}<0.01 * * * \mathrm{p}<0.001 .{ }^{1}$ Fixed parameter. 
As with previous research (Donovan \& Jessor, 1985), separate analyses were conducted for males and females and for different age groups (14 years old and under, 15-16 years old, and 17 years old and older). Data were analysed for the total sample also. Table 2 shows the $\mathrm{X}^{2}$ goodness of fit statistics and the Bentler-Bonett normed fit indices (Bender \& Bonett, 1980) for these analyses. Difference $\mathrm{X}^{2}$ values, which indicate the improvement in fit of each model compared with the model at the next lowest level of complexity, are shown also.

It is apparent from Table 2 that the simple one factor model (Model 1) does not fit the data adequately for any of the groups. In each case the probability level associated with the $\mathrm{X}^{2}$ goodness of fit test is less than 0.001. More importantly, the average fit index over the six subgroups was only 0.65 , indicating a poor fit. Therefore, Model 1 was rejected.

Although Model 2 significantly improved the fit over Model 1 for all groups, it still does not appear to be adequate. The $\mathrm{X}^{2}$ goodness of fit tests were significant at the 0.001 level and the average fit' index was 0.85 , below the generally accepted minimum value of 0.90 . Model 2 a significantly improved the fit for all age groups, but still does not appear to be satisfactory with an average fit index of 0.89 .

Model 3 appears to provide a more adequate representation of the data. This model was a significant improvement over Model 2a for all of the groups $\left(\mathrm{p}<0.001\right.$ in all cases). Although the $\mathrm{X}^{2}$ goodness of fit tests were still significant, the fit indices averaged 0.93 across the groups. Finally) Model 3a further improved the fit for each of the groups ( $\mathrm{p}<0.001$ for all comparisons). The fit indices for this model all exceeded 0.90 and averaged 0.96 . In addition, the mean absolute off- diagonal standardized residual was only 0.027 across the groups, indicating that the differences between the observed covariance matrices and those generated by the model were trivial. For the total sample, the fit index was 0.98 and the average standardized off-diagonal residual was 0.018 . Thus, Model 3a was accepted.

The standardized first order factor loadings from Model 3a are shown in Table 3. The overall factor patterns are remarkably similar for each of the age and gender groups. The items relating to smoking, drinking, marijuana use, and other drug use all loaded significantly on the first factor, those relating to lying and swearing all loaded significantly on the second factor, and those relating to stealing and vandalism loaded significantly on the third factor. Smoking and drinking also showed significant cross loadings on the minor problem behaviours factor for all of the groups.

Table 4. Standardised structural coefficients between general deviance and specific problem behaviours

\begin{tabular}{lrrr}
\hline & \multicolumn{3}{c}{ Factor } \\
\cline { 2 - 4 } Group & Drug Use & Minor Problem Behaviours & Serious Problem behaviours \\
\hline Males 14 years old and under & $0.24^{* *}$ & $0.86^{* *}$ & $0.89^{* *}$ \\
Females 14 years old and under & $0.38^{* *}$ & $0.90^{* *}$ & $0.87^{* *}$ \\
Males 15-16 years old & $0.43^{* *}$ & $0.86^{* *}$ & $0.89^{* *}$ \\
Females 15-16 years old & $0.43^{* *}$ & $0.85^{* *}$ & $0.81^{* *}$ \\
Males 17 years old and older & $0.41^{* *}$ & $0.78^{* *}$ & $0.85^{* *}$ \\
Females 17 years old and older & $0.28^{* *}$ & $0.87^{* *}$ & $0.81^{* *}$ \\
Total sample & $0.40^{* *}$ & $0.85^{* *}$ & $0.86^{* *}$ \\
\hline
\end{tabular}

*p $<0.01 * * \mathrm{p}<0.001$

The standardized structural coefficients relating general deviance to the specific factors are shown in Table 4. The square of these coefficients can be interpreted as indicating the percentage of variance in each specific factor that can be accounted for by the general deviance factor. It can be seen that general deviance accounts for substantially less of the variance in drug use $(X=14 \%)$, than in minor problem behaviours $(X=74 \%)$ or serious problem behaviours $(X=74 \%)$. The same figures for the total sample were $16 \%, 72 \%$ and $74 \%$, respectively. Thus, it appears that drug use behaviours among these young people are relatively independent of a general predisposition to engage in other deviant acts. 


\section{Discussion}

In contrast to previous studies of problem behaviours among adolescents and young adults from the United States, the present investigation did not find support for the general deviance hypothesis using data from Irish adolescents. Rather, at least three specific dimensions underlying problem behaviours were identified in this sample. These dimensions corresponded to (a) substance use, (b) relatively minor problem behaviours, and (c) relatively serious problem behaviours. A second order factor representing general tendency toward deviance was relatively weakly related to substance use and accounted for substantially less of the variance in these behaviours than in other problem behaviours.

One possible explanation for the apparent difference in the structure of problem behaviours among Irish and American youth concerns how behaviours become denned as deviant and the differential social acceptability of specific problem behaviours' across cultures and historical periods. In this case, drug use may have very different meanings in Ireland than in North America. Illicit drug use is very rare among Irish young people compared with their American counterparts and is highly disapproved by both peers and parents (Grube \& Morgan, 1986). As a result, unlike the case in North America, substance use may be seen as a relatively extreme form of deviance divorced from other problem behaviours. It thus seems important to carefully take into account the specific definitions and meanings attached to behaviours when applying problem behaviour theory within a given cultural setting.

It also is worth considering the general deviance hypothesis in the overall context of research on personality. The underlying premise of the general deviance hypothesis is that individuals are consistent in their actions across situations. Although the issue is a matter of some debate in psychology, a social learning approach to personality suggests that many behaviours are situation-specific and that broad traits are more the exception than the rule (cf. Mischel, 1984a, 1984b; Bandura, 1986). From this perspective, a person's behaviours are more guided by situationspecific expectancies, beliefs, and cognitive and behavioral competencies than they are by general traits. The more interesting question may be not so much why the present data did not reveal a unitary dimension of general deviance, as it is why such a pattern is found in North America.

Regardless of the interpretation, the present study indicates that among Irish adolescents, unlike American adolescents, drug use is relatively independent of an overall tendency towards deviance. These findings suggest that some aspects of the general deviance hypothesis may lack universality and may be culturally bound. The general deviance hypothesis, as it usually is assumed to apply to adolescent substance use, may be relevant only for adolescents from the United States and other similar cultural contexts. Future research should focus on clarifying the social and cultural conditions under which this hypothesis and problem behaviour theory) in general, hold true. 


\section{Acknowledgements}

This research was supported by funding from the Economic and Social Research Institute of Dublin, Ireland and the Commission of the European Communities. Support to the first author during the preparation of this manuscript was provided by National Institute on Alcohol Abuse and Alcoholism grant AA06282 to the Prevention Research Centre and the Pacific Institute for Research and Evaluation. The authors thank Patricia A. Madden and an anonymous reviewer for their helpful comments on an earlier draft of this manuscript.

\section{References}

BANDURA, A. (1986) Social Foundations of Thought and Action: A social cognitive theory (Englewood Cliffs, NJ, Prentice-Hall).

BENTLER, P. M. (1985) Theory and Implementation of EQS: a structural equations program (Los Angeles, BMDP Statistical Software, Inc.).

BENTLER, P. M. \& BONETT, D. G. (1980) Significance tests and goodness of fit in the analysis of covariance structures. Psychological Bulletin, 88, pp. 588-606.

DONOVAN, J. E. \& JESSOR, R. (1978) Adolescent problem drinking: Psychosocial correlates in a national sample study. Journal of Studies on Alcohol, 39, pp. 1506-1524.

DONOVAN, J. E. \& JESSOR, R. (1985) Structure of problem behavior in adolescence and young adulthood. Journal of Consulting and Clinical Psychology, 53, pp. 890-904.

GRUBE, J. W. \& MORGAN, M. (1986) Smoking, Drinking and Other Drug Use Among Dublin Post-primary Pupils (Dublin, The Economic and Social Research Institute).

GRUBE, J. W., MORGAN, M. \& KEARNEY, K. A. (1989) Using self-generated identification codes to match questionnaires in panel studies of adolescent substance use. Addictive Behaviors, 14, pp. 159-171.

JESSOR, R. \& JESSOR, S. L. (1977) Problem Behavior and Psychosocial Development: a longitudinal study of youth (New York, Academic Press).

JOHNSTON, L. D., O’MALLEY, P. M. \& EVELAND, L. K. (1978) Drugs and delinquency: A search for causal connections, in: D. B. KANDEL (Ed.) Longitudinal Research on Drug Use: empirical findings and methodological issues, pp. 137-156 (Washington DC, Hemisphere).

MISCHEL, W. (1984a) Convergences and challenges in the search for consistency, American Psychologist, 39, pp. 351-364.

MISCHEL, W. (1984b) On the predictability of behavior and the structure of personality, in: R. A. ZUCKER, J. ARNOFF \& A. I. RABIN (Eds) Personality and the Prediction of Behavior, pp. 269-305 (New York, Academic Press).

NEWCOMB, M. D. \& BENTLER, P. M. (1988) Consequences of Adolescent Drug Use: impact on the lives of young adults (Newbury Park, CA, Sage).

OSGOOD, D. W., JOHNSTON, L. D., (VMALLBY, P. M. \& BACHMAN, J. G. (1988) The generality of deviance in late adolescence and early adulthood, American Sociological Review, 53, pp. 81-93. 